\title{
0 projeto Resgate do Patrimônio Histórico e Cultural da UFRGS - contribuições da Lei Rovanet
}

\author{
Noemia Fatima Rodrigues ${ }^{1}$ \\ Judite Sanson Bem² \\ Zila Bernd ${ }^{3}$
}

\section{Resumo}

É assente a necessidade de proteção do patrimônio histórico e cultural edificado. Com os anos, as edificações apresentam desgaste, seja pelo tempo ou devido ao uso, necessitando, portanto, de conservação e preservação. Os prédios históricos da Universidade Federal do Rio Grande do Sul (UFRGS) remontam ao início do século XX, sendo o conjunto de doze prédios históricos considerado um patrimônio do estado do Rio Grande do Sul. As atividades necessárias à sua preservação envolvem elevados recursos financeiros, os quais não estavam contemplados integralmente no orçamento da UFRGS em 1999. Por essa razão, considerando a premente necessidade de restauração desses seus prédios e a indissociável demanda por mais recursos, a instituição buscou a Lei Federal de Incentivo à Cultura (8.313/91), conhecida como Lei Rouanet.

Palavras-chave: Lei Rouanet. Políticas públicas de financiamento à cultura. Patrimônio cultural. Preservação. Memória.

\section{Abstract}

It is understood the need for protection of historical and cultural heritage buildings. Over the years the buildings are worn either by time or due to use, requiring, therefore, conservation and preservation. The historic buildings of the Federal University of Rio Grande do Sul (UFRGS) date back to the early twentieth century, and the set of twelve historic buildings considered an asset of the state of Rio Grande do Sul. The activities necessary for the preservation of them involve high financial resources, which were not included in full in the budget of UFRGS in 1999. for this reason, considering the urgent need for restoration of its buildings and inseparable demand for resources, the institution sought in Federal Law for the Promotion of Culture (8313/91), known as Rouanet Law.

Keywords: Rouanet. Public policy financing culture. Cultural heritage. Preservation. Memory.

\footnotetext{
1 Mestre em Memória Social e Bens Culturais. Chefe do Setor de Patrimônio Histórico da Superintendência de Infraestrutura da Universidade Federal do Rio Grande do Sul (UFRGS).noemia03@yahoo.com.br

2 Doutora em História Ibero-Americana. Pós-Doutora em Economia da Cultura. Professora da Universidade de Caxias do Sul (UCS) e do Mestrado Profissional em Memória Social e Bens Culturais do Centro Universitário La Salle (Unilasalle). jsanson@terra.com.br

3 Doutora e Pós-Doutora em Letras. Professora aposentada do PPG em Letras da Universidade Federal do Rio Grande do Sul (UFRGS). Professora do PPG em Memória Social e Bens Culturais do Centro Universitário La Salle (Unilasalle). zilabster@gmail.com
} 


\section{Introdução}

Ao longo do século $X X$, cresceu a preocupação das nações com a preservação do patrimônio cultural, notadamente devido à atuação de organizações internacionais como a Organização das Nações Unidas (ONU), a Organização das Nações Unidas para Educação, Ciência e Cultura (UNESCO) e o Conselho Internacional de Monumentos e Sítios (ICOMOS). Nesse cenário, constata-se a importância da preservação do patrimônio cultural para a humanidade.

O Brasil ingressou no século XXI, envidando esforços para aprimorar a proteção do seu patrimônio cultural. Não é raro constatar nas cidades brasileiras edificações e monumentos se deteriorando devido às intempéries e à falta de conservação. Para proteger o patrimônio cultural brasileiro, a Constituição Federal de 1988 atribuiu obrigações e responsabilidades ao Estado e aos cidadãos. Assim, o Estado e a sociedade devem se empenhar na construção de meios para recuperar e revitalizar o patrimônio cultural pátrio.

Por conseguinte, a necessidade de proteção dos bens que compõem o patrimônio cultural edificado do país é assente, uma vez que, com o passar dos anos, as edificações apresentam desgastes pela passagem do tempo e pelo seu uso. Diante dessas condições, os edifícios históricos demandam serviços especializados de conservação e de preservação.

A UFRGS foi criada em 1934, sendo uma das mais antigas universidades públicas do país. Sua estrutura física está distribuída pelos municípios de Porto Alegre, Gramado, Eldorado do Sul, Tramandaí, Imbé e Capão Novo. Na cidade de Porto Alegre, a instituição estrutura-se em quatro campi: Centro, Olímpico, Saúde e do Vale. No Campus Centro, convivem duas gerações históricas e artísticas de edificações dos séculos XIX e XX.

O primeiro grupo é composto por onze edifícios construídos entre 1898 e 1928, distribuídos entre dois quarteirões de área edificada, com delimitação conformada pelas Avenidas João Pessoa, Osvaldo Aranha, Paulo da Gama, pela Rua Engenheiro Luiz Englert e pela Praça Argentina. Esse conjunto apresenta características dos estilos Eclético ${ }^{4}$ e Art Noveau. ${ }^{5}$

Esses edifícios, com o passar dos anos, apresentaram desgastes inerentes à passagem do tempo e ao seu uso. Ocorre que a Universidade, no ano de 1999, não dispunha, em seu orçamento, de recursos financeiros, na sua integralidade, para custear as obras de restauro. Por essa razão, considerando a necessidade de restauração dos seus prédios e a indissociável demanda por mais recursos, a UFRGS buscou na Lei Rouanet e em outras fontes a receita extraorçamentária de

\footnotetext{
${ }^{4}$ Ecletismo na arquitetura: uso livre de elementos de vários estilos, inclusive em um mesmo edifício, cujo auge foi alcançado como uma expressão do Historicismo na segunda metade do século XX, além de desempenhar um importante papel no PósModernismo (ENCYCLOPEDIA OF 20th, 1987).

${ }^{5} \mathrm{Na}$ arquitetura, as obras Art Noveau demonstram o propósito de acabar com a imitação dos estilos do passado, produzindo uma arquitetura florida, que cultiva o artesanato, os materiais coloridos e os revestimentos exóticos, valendo-se de linhas curvas no formato das aberturas e elementos decorativos (ENCYCLOPEDIA OF 20th, 1987).
} 
que necessitava.

A Lei Rouanet instituiu o Programa Nacional de Apoio à Cultura (PRONAC), com a finalidade precípua de captar e canalizar recursos financeiros para estimular a produção, a difusão dos bens culturais, e preservar os bens materiais e imateriais do patrimônio cultural e histórico brasileiro.

Nesse cenário, foi concebido e se desenvolveu o projeto "Resgate do $\mathrm{Pa}$ trimônio Histórico e Cultural da UFRGS" em 1999. Por meio dele, a universidade está restaurando os seus prédios históricos da primeira geração. Essas edificações são obras de inestimável valor arquitetônico e histórico, importantes para a preservação da memória da universidade e da história sociocultural de Porto Alegre.

Desse modo, a pesquisa analisou as contribuições da Lei Rouanet para o projeto "Resgate do Patrimônio Histórico e Cultural da UFRGS", no período de 1999 a 2013, um estudo de caso. Com o projeto "Resgate do Patrimônio Histórico e Cultural da UFRGS", a Universidade Federal do Rio Grande do Sul se propôs a recuperar doze prédios construídos para abrigar os primeiros cursos de graduação no estado do Rio Grande do Sul, entre 1898 e 1928, conhecidos com prédios da primeira geração.

O objetivo deste artigo é apresentar o projeto "Resgate do Patrimônio Histórico e Cultural da UFRGS", por meio da análise do estado de conservação dos prédios históricos da instituição, na década de 1990, e dos valores captados pela Lei Federal de Incentivo à Cultura (Lei Rouanet) para a sua restauração, no período compreendido entre 1999 e 2013.

Metodologicamente, o artigo trata-se de uma investigação descritiva, documental e bibliográfica. Os dados financeiros, oriundos do Setor de Patrimônio Histórico da UFRGS e do Ministério da Cultura, são tratados na forma da estatística descritiva.

\section{Estado de conservação dos prédios históricos no final da década de 1990}

A UFRGS possui um acervo edificado de valor histórico-cultural, no contexto urbano da cidade de Porto Alegre, cuja construção desenvolveu-se em dois momentos. Primeiramente, entre os anos de 1898 e 1928, foram erigidas doze edificações que constituem o conjunto denominado de prédios históricos da UFRGS da "primeira geração". Onze dessas edificações estão localizadas no Campus Centro, e uma, o prédio da Faculdade de Agronomia, no Campus do Vale, as quais são consideradas patrimônio cultural do Rio Grande do Sul pela Lei no 11.525, de 15 de setembro de 2000 (RIO GRANDE DO SUL, 2000). Destaca-se, ainda, que duas são tombadas pelo Instituto do Patrimônio Histórico e Artístico Nacional (IPHAN): os prédios da Faculdade de Direito e do Observatório Astronômico.

Entre os anos de 1996 e 1998, foi realizado um inventário que demonstrou o quanto as edificações históricas da primeira geração da UFRGS estavam castigadas pelo tempo e pelo uso, necessitando, assim, de preservação e manutenção para que pudessem continuar cumprindo com as suas funções de abrigar o ensino, a pesquisa e a extensão. 
Nesse período, por exemplo, havia dois prédios interditados por medida de segurança. Para reverter essa situação, foi necessário encontrar uma fonte extra de recursos para arcar com os custos das restaurações, as quais extrapolavam as despesas ordinárias da universidade.

Com a finalidade de demonstrar a situação em que se encontravam os prédios históricos da UFRGS, em 1998, apresentam-se os Quadros 1, 2 e 3, nos quais se elaborou um resumo do inventário de proteção de acervo cultural da UFRGS realizado naquele ano.

\section{Quadro 1- Primeiro Quarteirão - Campus Centro}

\begin{tabular}{|c|c|c|}
\hline $\begin{array}{l}\text { PRÉDIOS/ } \\
\text { ANO DE } \\
\text { CONSTRUÇÃO }\end{array}$ & $\begin{array}{l}\text { OBRAS APONTADAS COMO } \\
\text { NECESSÁRIAS EM } 1998\end{array}$ & OBSERVAÇÕES \\
\hline $\begin{array}{l}\text { ESCOLA DE } \\
\text { ENGENHARIA } \\
1901\end{array}$ & $\begin{array}{l}\text { Recuperar a cobertura, os pisos } \\
\text { (estágio precário), as esquadrias, } \\
\text { as instalações elétricas e hidros- } \\
\text { sanitárias e a pintura original. }\end{array}$ & --- \\
\hline $\begin{array}{l}\text { CHÂTEAU } \\
1906 / 1908\end{array}$ & $\begin{array}{l}\text { Recuperar a cobertura, as insta- } \\
\text { lações elétricas e hidrossanitá- } \\
\text { rias, as aberturas, os elementos } \\
\text { que compõem a fachada externa } \\
\text { e a pintura original. }\end{array}$ & $\begin{array}{l}\text { A edificação apresentava } \\
\text { graves problemas pela falta } \\
\text { de manutenção, sendo } \\
\text { interditada por medida de } \\
\text { segurança. O seu telhado } \\
\text { chegou a desabar pela } \\
\text { deterioração das estruturas } \\
\text { de madeira. }\end{array}$ \\
\hline $\begin{array}{l}\text { CASTELINHO } \\
1906 / 1908\end{array}$ & $\begin{array}{l}\text { Recuperar a fachada original, } \\
\text { os elementos ornamentais e a } \\
\text { pintura. }\end{array}$ & $\begin{array}{l}\text { Falta de manutenção e con- } \\
\text { servação. }\end{array}$ \\
\hline $\begin{array}{l}\text { OBSERVATÓ- } \\
\text { RIO ASTRONÔ- } \\
\text { MICO } \\
1908\end{array}$ & $\begin{array}{l}\text { Recuperar a cúpula metálica, a } \\
\text { impermeabilização na cobertura } \\
\text { e a pintura original. }\end{array}$ & $\begin{array}{l}\text { As alvenarias e as pinturas } \\
\text { murais estavam desgasta- } \\
\text { das pela umidade e pela } \\
\text { falta de manutenção. }\end{array}$ \\
\hline $\begin{array}{l}\text { INSTITUTO } \\
\text { ELETROTÉC- } \\
\text { NICO } \\
1910\end{array}$ & $\begin{array}{l}\text { Recuperar os elementos decora- } \\
\text { tivos internos, os figurativos das } \\
\text { fachadas, a impermeabilização } \\
\text { da cobertura e a pintura. }\end{array}$ & $\begin{array}{l}\text { Falta de manutenção e con- } \\
\text { servação. }\end{array}$ \\
\hline $\begin{array}{l}\text { INSTITUTO } \\
\text { PAROBÉ } \\
1928\end{array}$ & $\begin{array}{l}\text { Recuperar a cobertura com as } \\
\text { suas três cúpulas de cobre e a } \\
\text { pintura original }\end{array}$ & $\begin{array}{l}\text { Falta de manutenção e con- } \\
\text { servação. }\end{array}$ \\
\hline $\begin{array}{l}\text { FACULDADE DE } \\
\text { DIREITO } \\
1910\end{array}$ & $\begin{array}{l}\text { Recuperar a pintura mural, os } \\
\text { elementos decorativos e a pintu- } \\
\text { ra original. }\end{array}$ & $\begin{array}{l}\text { Falta de manutenção e } \\
\text { conservação. }\end{array}$ \\
\hline TOTAL: 7 & --- & --- \\
\hline
\end{tabular}

Fonte: Rodrigues (2015). 
A Figura 1 demonstra o estado de conservação do prédio do Château antes das obras de restauro.

Figura 1 - Fotos do Château - antes do restauro

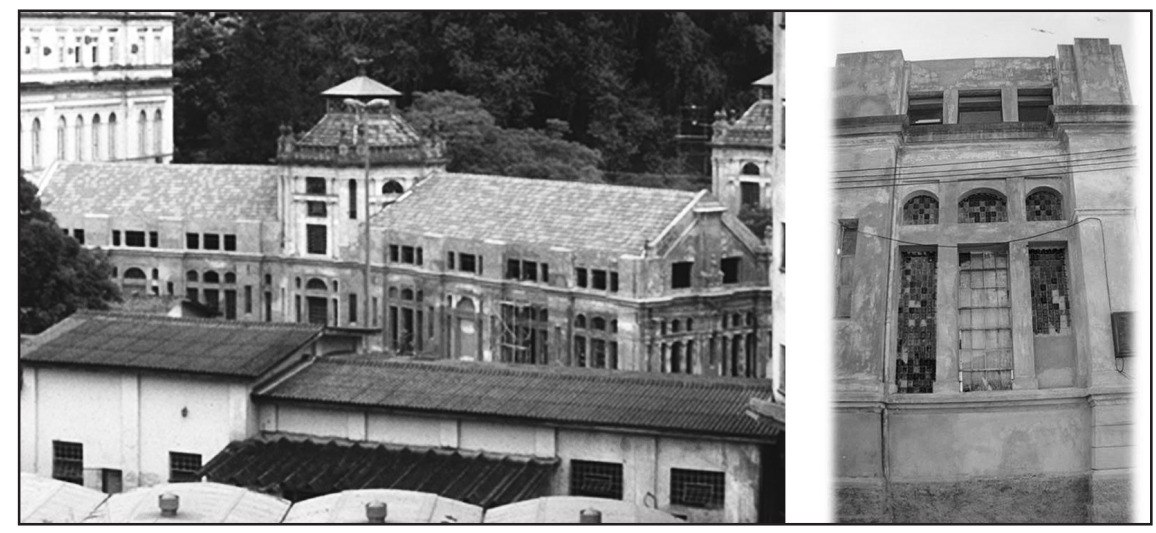

Fonte: UFRGS $(2004 ; 1998 b)$.

Este edifício abrigou as oficinas de marcenaria, carpintaria, serralheria, sala de máquinas, almoxarifado e ambulatório da Escola de Engenharia. Trata-se de uma edificação que testemunhou os primeiros passos da Escola Técnica do Rio Grande do Sul.

No Quadro 2, inserido na próxima página, são apresentados os prédios integrantes do segundo quarteirão. 


\begin{tabular}{|c|c|c|}
\hline $\begin{array}{l}\text { PRÉDIOS / ANO } \\
\text { DE CONSTRUÇÃO }\end{array}$ & $\begin{array}{c}\text { OBRAS APONTADAS } \\
\text { COMO NECESSÁRIAS } \\
\text { EM } 1998\end{array}$ & OBSERVAÇÕES \\
\hline $\begin{array}{l}\text { RÁDIO DA } \\
\text { UNIVERSIDADE } \\
1908\end{array}$ & $\begin{array}{l}\text { Recuperar a pintura } \\
\text { original. }\end{array}$ & $\begin{array}{l}\text { Havia infiltrações na cobertura } \\
\text { e no terraço, as quais causavam } \\
\text { danos nos espaços interiores, } \\
\text { bem como na alvenaria, no } \\
\text { reboco e nos elementos de } \\
\text { madeira. }\end{array}$ \\
\hline $\begin{array}{l}\text { MUSEU } \\
\text { UNIVERSITÁRIO } \\
\text { (CURTUMES E } \\
\text { TANANTES) } \\
1913\end{array}$ & $\begin{array}{l}\text { Recuperar a cobertura, } \\
\text { os elementos } \\
\text { ornamentais, as } \\
\text { aberturas, os sistemas } \\
\text { elétrico e hidrossanitário } \\
\text { e a pintura original. }\end{array}$ & $\begin{array}{l}\text { A cobertura apresentava } \\
\text { falta de telhas e deformação. } \\
\text { As paredes apresentavam } \\
\text { infiltrações e rachaduras, } \\
\text { sendo que, em alguns pontos, } \\
\text { não havia mais reboco. O } \\
\text { mezanino e a escada de acesso } \\
\text { a este estavam parcialmente } \\
\text { destruídos pela ação dos } \\
\text { cupins. As esquadrias estavam } \\
\text { praticamente sem vidros } \\
\text { pelo desgaste e pela falta de } \\
\text { manutenção. Foi interditado } \\
\text { por medida de segurança. }\end{array}$ \\
\hline $\begin{array}{l}\text { ANTIGO PRÉDIO } \\
\text { DA FACULDADE } \\
\text { DE MEDICINA } \\
1924\end{array}$ & $\begin{array}{l}\text { Restaurar o Salão Nobre, } \\
\text { recuperar os elementos } \\
\text { decorativos da fachada, } \\
\text { a pintura e substituir o } \\
\text { sistema mecânico de } \\
\text { ventilação. }\end{array}$ & $\begin{array}{l}\text { A ação do tempo e a falta } \\
\text { de manutenção levaram à } \\
\text { deterioração do reboco, das } \\
\text { esquadrias, das estruturas } \\
\text { de madeira da cobertura, } \\
\text { dos pisos e dos elementos } \\
\text { decorativos. }\end{array}$ \\
\hline $\begin{array}{l}\text { antigo prédio } \\
\text { do Instituto de } \\
\text { Química } \\
1926\end{array}$ & $\begin{array}{l}\text { Restaurar a cobertura, } \\
\text { os pisos, os sistemas } \\
\text { elétrico e hidrossanitário } \\
\text { e a pintura original. }\end{array}$ & $\begin{array}{l}\text { O edifício apresentava } \\
\text { infiltrações e problemas de } \\
\text { umidade. }\end{array}$ \\
\hline TOTAL: 4 & --- & --- \\
\hline
\end{tabular}

Fonte: Rodrigues (2015).

A Figura 2 evidencia a deterioração em que se encontrava o prédio do "Curtume e Tanantes". Essa edificação possui na fachada um frontão adornado por uma pintura que simboliza o trabalho, o qual estava invisível devido ao desgaste da construção. Esse edifício foi construído para abrigar o laboratório de resistência de materiais da Escola de Engenharia, órgão de vanguarda na pesquisa de novas tecnologias no início do século XX. Após, o prédio foi ocupado pelo Curso de Tecnologia do Couro, fato este que o tornou conhecido como "Curtumes e Tanantes". 
Figura 2 - Foto do "Curtumes e Tanantes" antes do restauro (atual museu da UFRGS)

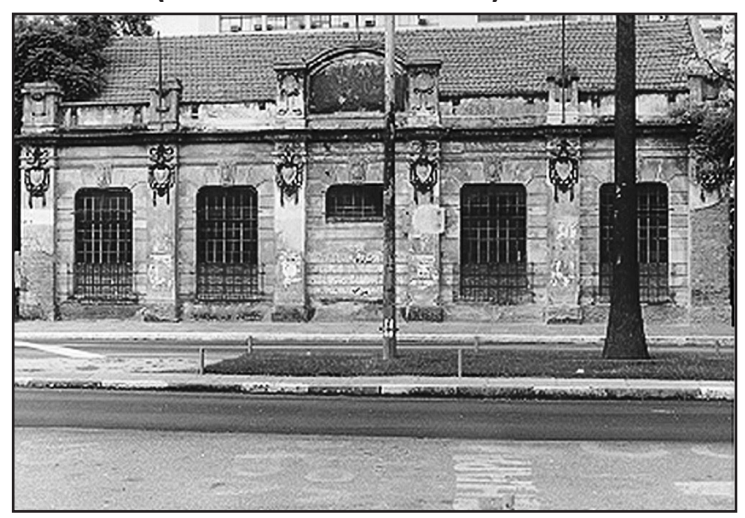

Fonte: UFRGS (2004; 1998b).

O Quadro 3 apresenta um resumo sintético do estado de conservação do edifício central da Faculdade de Agronomia, no Campus do Vale.

Quadro 3 - Campus do Vale

\begin{tabular}{|l|l|l|}
\hline $\begin{array}{c}\text { PRÉDIOS / ANO } \\
\text { DE CONSTRUÇÃO }\end{array}$ & $\begin{array}{c}\text { OBRAS APONTADAS } \\
\text { COMO NECESSÁRIAS } \\
\text { EM 1998 }\end{array}$ & \multicolumn{1}{c|}{ OBSERVAÇÕES } \\
\hline $\begin{array}{l}\text { FACULDADE DE } \\
\text { AGRONOMIA } \\
1913\end{array}$ & $\begin{array}{l}\text { Recuperar a cobertura, } \\
\text { os pisos, as esquadrias, } \\
\text { as instalações elétricas } \\
\text { e hidrossanitárias e a } \\
\text { pintura original. }\end{array}$ & $\begin{array}{l}\text { A edificação apresentava } \\
\text { vários problemas. Chegou a } \\
\text { ser parcialmente interditada } \\
\text { por medida de segurança. O } \\
\text { forro do último pavimento, } \\
\text { módulo central, desabou pela } \\
\text { ação do tempo e pela falta de } \\
\text { manutenção. }\end{array}$ \\
\hline TOTAL: 1 & --- & - \\
\hline
\end{tabular}

Fonte: Rodrigues (2015).

A Figura 3 demonstra o precário estado de conservação em que se encontrava o prédio da Faculdade de Agronomia antes das obras de restauro. 
Figura 3 - Foto do prédio da Faculdade de Agronomia antes do restauro

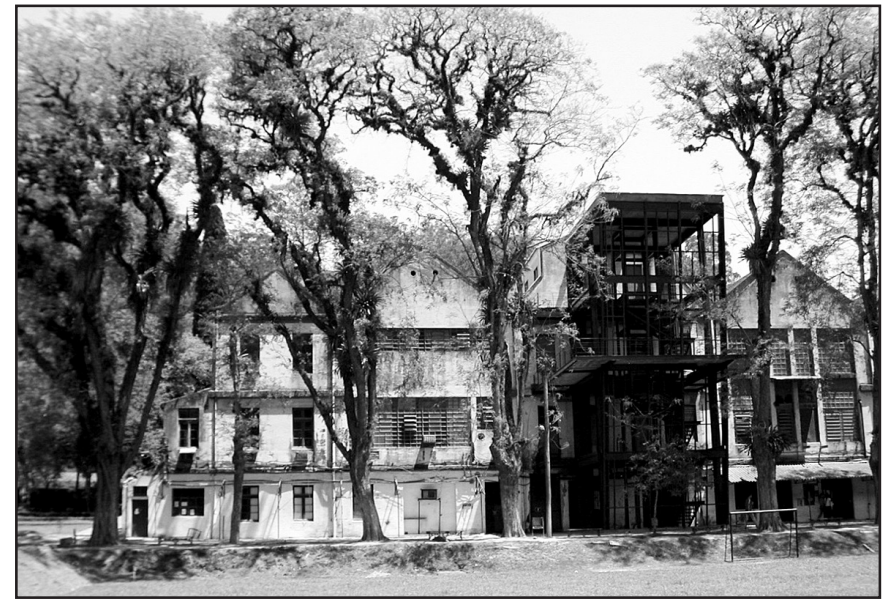

Fonte:UFRGS $(2004 ; 1998 b)$.

Esse edifício foi construído com o auxílio do governo do Estado do Rio Grande do Sul. A estrutura de funcionamento foi inspirada em modelo norteamericano, com foco no ensino prático-teórico, na pesquisa e na extensão rural.

Como visto nas Figuras 1, 2 e 3, é evidente o estado de deterioração em que se encontravam os prédios históricos da UFRGS antes da implantação do projeto "Resgate do Patrimônio Histórico e Cultural da UFRGS".

\section{0 projeto Resgate do Patrimônio Histórico e Cultural da UFRGS}

No primeiro reitorado da professora Wrana Maria Panizzi, de 1996 a 2000, foi implementado o projeto "Resgate do Patrimônio Histórico e Cultural da UFRGS", o qual surge em consequência do inventário realizado no período compreendido entre 1996-1998, em que se constatou o quanto os prédios históricos da primeira geração, construídos entre os anos de 1898 e 1928, estavam desgastados pelo tempo e pelo uso. Dois desses prédios chegaram, inclusive, a ser interditados por questões de segurança: o prédio do Château e o do "Curtumes e Tanantes".

Em 1998, foi editado o livro "Os Prédios Históricos da UFRGS: Atualidade e Memória", em português e inglês. Com essa publicação, desejava-se atrair a atenção para a importância da preservação deste significativo patrimônio para a comunidade acadêmica e para a sociedade. No mesmo ano, foi encaminhado o pedido de tombamento do conjunto arquitetônico do Campus centro à 12 a Superintendência Regional do Instituto do Patrimônio Histórico e Artístico Nacional (IPHAN).

O pedido da UFRGS foi encaminhado ao Ministério da Cultura/IPHAN, com parecer favorável do Superintendente da Regional Sul, o arquiteto Luiz Fernando Rhoden. O pleito em comento incluía os doze prédios construídos entre os anos 
de 1898 e 1928 e o prédio da Reitoria. O pedido de tombamento visava conferir uma maior proteção ao patrimônio cultural edificado e à aprovação do projeto pelo Ministério da Cultura (PRONAC) para o financiamento das obras de restauro por meio da Lei Rouanet. Em outubro de 1999, o IPHAN aprovou o tombamento dos prédios da Faculdade de Direito e do Observatório Astronômico.

Na sequência, em 1999, o projeto "Resgate do Patrimônio Histórico e Cultural da UFRGS" foi aprovado pelo Ministério da Cultura, por meio da Portaria no 393, de 28 de outubro de 1999, publicada no Diário Oficial da União (DOU), em 10 de novembro do mesmo ano, inserido no Programa Nacional de Apoio à Cultura (PRONAC), na modalidade Incentivo Fiscal da Lei de Incentivo à Cultura (Lei Rouanet). A partir desse momento, a UFRGS estava autorizada a captar recursos da iniciativa privada, por meio de doações e patrocínios de pessoas físicas e jurídicas, respectivamente.

Em suma, esse projeto contempla dois objetivos fundamentais: (i) recuperar e preservar os prédios históricos, de imenso significado cultural, os quais estavam desgastados pelo tempo e pelo uso, devolvendo-os à comunidade acadêmica e à população em geral, para se (re)integrarem ao cotidiano das atividades de ensino, pesquisa e extensão da Universidade, e (ii) resolver parcela das carências e das demandas por espaço físico que a universidade enfrenta, dada a sua constante ampliação (PANIZZI, 2004).

Com a expedição da Portaria no 393/1999, a UFRGS começou a captação de recursos para a restauração dos seus prédios históricos, iniciando, assim, uma "nova fase" de relacionamento com a sociedade, a qual foi estimulada a conhecer e a participar do projeto "Resgate do Patrimônio Histórico e Cultural".

Na primeira edição do Dia da Doação', em dezembro de 1999, a UFRGS captou o montante de $\mathrm{R} \$ 269.456,73$ (duzentos e sessenta e nove mil, quatrocentos e cinquenta e seis reais e setenta e três centavos7), valor que, corrigido até

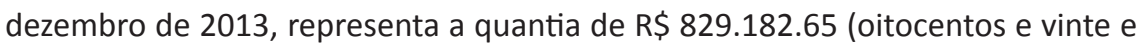
nove mil, cento e oitenta e dois reais e sessenta e cinco centavos8).

Nesse dia de captação, foram arrecadados os recursos necessários para a obra de restauro do prédio do Observatório Astronômico, no valor de $\mathrm{R} \$ 128.698,86$ (cento e vinte e oito mil, seiscentos e noventa e oito reais e oitenta e seis centavos), por um patrocinador único, pessoa jurídica9. Esse valor, se corrigido até dezembro de 2013, representa a quantia de $\mathrm{R} \$ 396.037,10$ (trezentos e noventa e seis mil e trinta e sete reais e dez $\operatorname{centavos}^{10}$ ).

\footnotetext{
${ }^{7} \mathrm{O}$ evento tem o objetivo de arrecadar fundos para a conservação e restauração dos prédios históricos da Universidade (LUME, 2017)

8 Controles internos do SPH/UFRGS.

8 Valor corrigido pelo Índice Geral de Preços de Mercado (IGP-M - FGV). Valor atualizado até dezembro de 2013 por ser este o limite do lapso temporal abrangido pela presente investigação.

${ }^{9}$ Controles internos do SPH/UFRGS.

${ }^{10}$ Valor corrigido pelo Índice Geral de Preços de Mercado (IGP-M - FGV). Valor atualizado até dezembro de 2013 por ser este o limite do lapso temporal abrangido pela presente investigação.
} 
A Figura 4 mostra o prédio histórico do Observatório Astronômico após o processo de restauro.

Figura 4 - Foto do Observatório - após o restauro

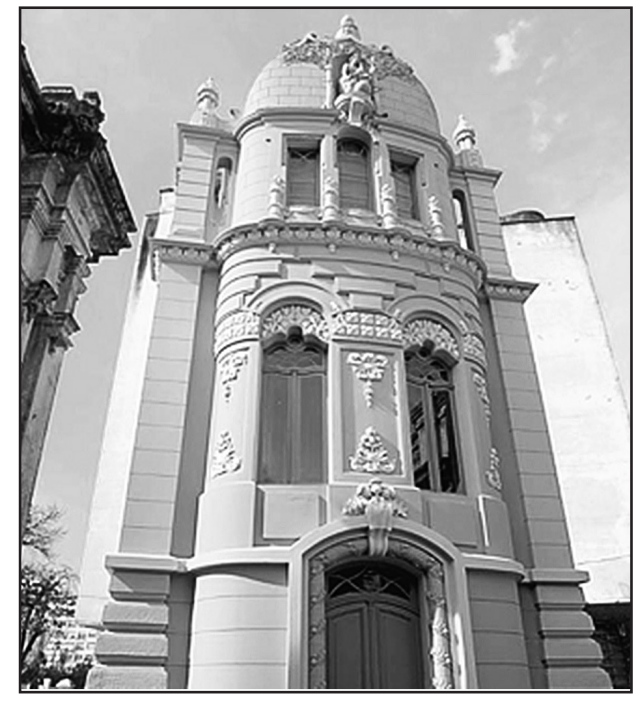

Fonte: UFRGS (2004; 1998b).

\section{Valores e destinação dos recursos captados de 1999 a 2013}

No período compreendido entre 1999 e 2013, a UFRGS arrecadou um montante de $\mathrm{R} \$ \mathbf{1 9 . 4 0 6 . 0 0 7 , 5 9}$, dos quais 54,87\% são oriundos da Lei Rouanet, ou seja, $\mathrm{R} \$ 10.647 .767,81$. Dentro do valor captado através da Lei Rouanet, por sua vez, observa-se a seguinte distribuição entre os incentivadores: $32,38 \%$ dos recursos são provenientes de pessoas físicas, e 67,62\%, de pessoas jurídicas.

Do montante total de $\mathrm{R} \$ 1$ 19.406.007,59 arrecadados, os 45,13\% restantes têm como origem as seguintes fontes: Lei Estadual de Incentivo à Cultura - PróCultura: 12,96\%; Emendas Parlamentares: 11,85\%; Programa de Aceleração do Crescimento (PAC) das cidades históricas: 7,73\%; recursos da UFRGS: $6,04 \%$; convênios: 3,33\%; e outros recursos: $3,22 \%$.

O balanço das restaurações até 31 de dezembro de 2013 apresenta os seguintes resultados: (i) foram restaurados sete prédios históricos, do total de doze edificações, sendo eles: Curtumes e Tanantes (atual Museu da UFRGS), Observatório Astronômico, Rádio da Universidade, Château, Faculdade de Direito, Castelinho e Faculdade de Agronomia; (ii) já foram realizadas obras parciais em outras edificações, como a implantação de acessibilidade no prédio da antiga Faculdade de Medicina (parcial) e os reparos nas cúpulas do Instituto Parobé, por exemplo; (iii) o prédio da Escola de Engenharia, que será o oitavo a ser concluído, está na fase final das obras de restauro; e (iv) o prédio do Instituto Parobé, que será o nono a ser concluído, está em obras para a implantação de acessibilidade 
no núcleo central.

A título de exemplo, apresentam-se, nas figuras 5, 6 e 7, as imagens dos prédios do "Curtumes e Tanantes", do Château e da Faculdade de Agronomia, que foram restaurados e reintegrados às atividades da instituição nos anos de 2002, 2004 e 2009, respectivamente.

\section{Figura 5 - Fotos do "Curtumes e Tanantes"- após o restauro} (atual Museu da UFRGS)

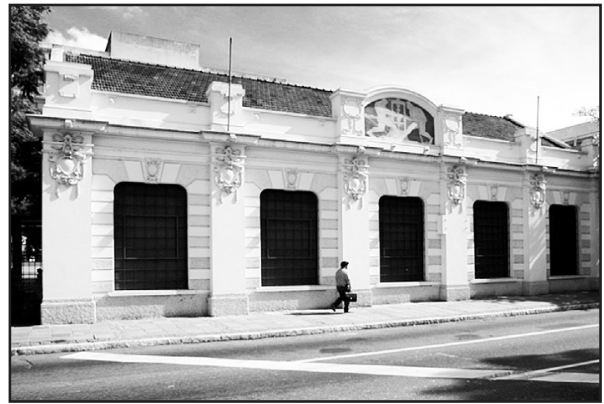

Fonte: UFRGS $(2004 ; 1998 b)$.

Figura 6 - Foto do prédio do Château - após o restauro

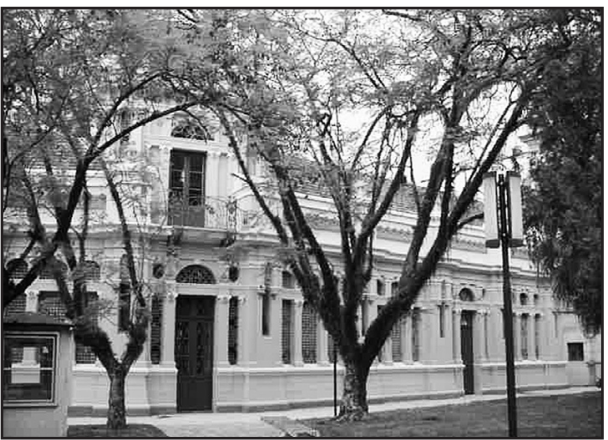

Fonte: UFRGS (2004; 1998b).

Figura 7 - Foto do prédio da Faculdade de Agronomia - após o restauro

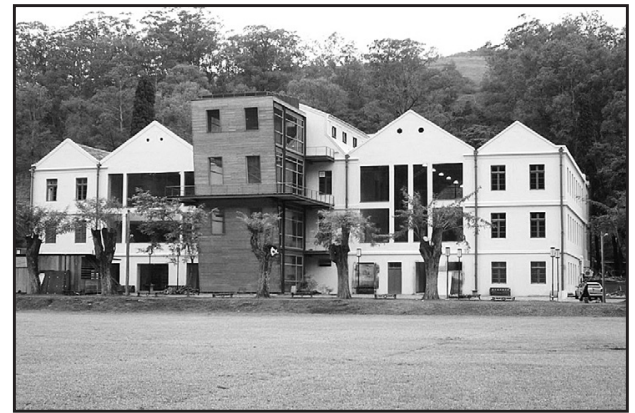

Fonte: UFRGS (2004; 1998b). 
Nesse contexto, também ganham relevo e reconhecimento as realizações do Projeto da UFRGS. Ele já recebeu vários prêmios nacionais e internacionais, como o Prêmio Rodrigo Melo Franco de Andrade, do IPHAN ${ }^{11}$, nos anos 2000, 2001, 2002 e 2006; o IV Prêmio Joaquim Felizardo, da Secretaria Municipal de Cultura da Prefeitura de Porto Alegre, em 2010; e o VII Prêmio Internacional Rainha Sofia de Conservação e Restauração do Patrimônio Cultural, em $2011^{12}$.

\section{Considerações finais}

O Brasil ingressou no século XXI com a necessidade de aprimorar a proteção do seu patrimônio cultural. Os bens culturais, materiais e imateriais, são testemunhos vivos da história da sociedade brasileira. Fazem parte do imaginário coletivo nacional, compondo os sentidos de coletividade e de pertencimento ao país. Preservar o legado cultural do povo brasileiro consiste em criar condições para que este permaneça. Conservá-lo de modo democrático e com consciência intergeracional implica criar condições para que seja conhecido pela geração do presente e exista para a sociedade do futuro.

A preservação do patrimônio cultural edificado contribui para a preservação da memória coletiva da sociedade. A memória é relacional e pode ser evocada por uma série de elementos externos ao indivíduo, como o aspecto material das cidades, os objetos e os prédios, os quais podem funcionar como pontos de apoio para a recordação. A historicidade das edificações Ihes atribui uma representatividade qualificada, de relevante significado social e cultural, que precisa ser considerada, valorada e protegida.

Os prédios históricos da UFRGS são referência para a memória coletiva de milhares de indivíduos - alunos, ex-alunos, servidores públicos, sociedade porto -alegrense, dentre outros. Ademais, muitas destas edificações foram construídas graças ao esforço da comunidade rio-grandense e dos seus fundadores. Tanto que parte dos recursos foi captada em quermesses, bailes, livros de ouro, campanhas de donativos e doações de outros municípios. Por consequência, este patrimônio cultural edificado é permeado e envolto de significados simbólicos, fazendo reviver memórias e despertando sentimentos de identidade e de pertencimento.

O projeto "Resgate do Patrimônio Histórico e Cultural da UFRGS", ao recuperar esses prédios, revigora a importância social desse patrimônio cultural edificado, que merece proteção por firmar e confirmar a engenhosidade, a história e o imaginário das gerações passadas.

A Lei Rouanet instituiu um novo formato para o financiamento da cultura no país, legitimando os projetos culturais por meio de orçamentos pré-aprovados e pela instituição da obrigatoriedade da democratização do acesso aos bens,

11 O Prêmio Rodrigo Melo Franco de Andrade é um dos maiores prêmios nacionais na área de preservação do patrimônio cultural.

12 Por unanimidade do corpo de jurados, foi concedida a Menção Honrosa pela Agencia Española de Cooperación Internacional para el Desarrollo, do Ministerio de Asuntos Exteriores y de Cooperación. A própria Rainha Sofia procedeu à entrega da placa e do diploma à UFRGS, em cerimônia realizada na Espanha em 2012 (UFRGS, 2011). 
produtos e serviços culturais, bem como de medidas que promovem a acessibilidade aos espaços e produtos culturais, para idosos e pessoas com deficiência ou mobilidade reduzida, além de cotas de ingressos a preços populares. Para os prédios históricos da UFRGS, a Lei Rouanet abriu caminhos para a colaboração dos incentivos em prol do patrimônio cultural edificado da instituição. Ao longo dos anos, essa ação participativa se consolidou, fortalecendo o sentimento de pertencimento da comunidade acadêmica e da sociedade em geral.

Como visto, pela análise dos dados e das imagens apresentadas, a implantação do projeto em comento ocorreu em um momento decisivo, pois era premente e necessária uma intervenção restaurativa e adaptada às demandas contemporâneas nas suas doze edificações históricas. Se a iniciativa do projeto tardasse, corria-se o risco de que alguns desses edifícios ficassem descaracterizados, o que traria uma perda irremediável para o patrimônio cultural da UFRGS e da sociedade rio-grandense.

\section{Referências}

BRASIL. Lei Federal no 8.313 de 1991. Restabelece princípios da Lei n 7.505, de 2 de julho de 1986, institui o Programa Nacional de Apoio à Cultura (Pronac) e dá outras providências. Disponível em: <www.planalto.gov.br>. Acesso em: 7 jun. 2017.

ENCYCLOPEDIA OF 20th. Century Architecture. New York: Abrams, 1987.

LUME. Repositório Digital. Disponível em: <http://www.lume.ufrgs.br/handle/ 10183/131847>. Acesso em: 7 jun. 2017.

PANIZZI, Wrana Maria. Introdução. In: UFRGS. Patrimônio Histórico e Cultural da UFRGS. Porto Alegre: UFRGS, 2004.

RIO GRANDE DO SUL. Lei Estadual no 11.525/2000. Declara integrantes do patrimônio cultural do Estado os prédios históricos da Universidade Federal do Rio Grande do Sul. Disponível em: <http://www.al.rs.gov.br/filerepository/ repLegis/arquivos/11.525.pdf>. Acesso em: 31 mar. 2015.

RODRIGUES, Noemia Fatima. Contribuições da Lei Rouanet para o Projeto Resgate do Patrimônio Histórico e Cultural da UFRGS. 2015.

UFRGS. Universidade Federal do Rio Grande do Sul. Inventário de Proteção do Acervo Cultural da UFRGS. Primeiro Campus Universitário do Brasil. Primeira Universidade Técnica. Porto Alegre, 1998a. Não publicado.

. Os prédios históricos da UFRGS: atualidade e memória. Porto Alegre: UFRGS, $1998 \mathrm{~b}$.

Patrimônio Histórico e Cultural da UFRGS. Organizado Secretaria do Patrimônio Histórico. Porto Alegre: UFRGS, 2004.

. Prêmio Rainha Sofia, 2011. Dossiê encaminhado à 7ạ edição do Prêmio Reina Sofia de Conservação e Restauração do Patrimônio Cultural. Categoria Patrimônio Material. Premiado com Menção Honrosa. Não publicado. 